\title{
Legionella on board trains: effectiveness of environmental surveillance and decontamination
}

\author{
Gianluigi Quaranta ${ }^{1}$, Sara Vincenti ${ }^{*}$, Anna Maria Ferriero ${ }^{1}$, Federica Boninti ${ }^{1}$, Romina Sezzatini ${ }^{1}$, Cinzia Turnaturi ${ }^{1}$, \\ Maria Daniela Gliubizzi ${ }^{1}$, Elio Munafòㄹ, Gianluca Ceccarelli², Carmelo Causarano², Massimo Accorsi², \\ Pasquale Del Nord ${ }^{3}$, Walter Ricciardi ${ }^{1}$ and Patrizia Laurenti ${ }^{1}$
}

\begin{abstract}
Background: Legionella pneumophila is increasingly recognised as a significant cause of sporadic and epidemic community-acquired and nosocomial pneumonia. Many studies describe the frequency and severity of Legionella spp. contamination in spa pools, natural pools, hotels and ships, but there is no study analysing the environmental monitoring of Legionella on board trains. The aims of the present study were to conduct periodic and precise environmental surveillance of Legionella spp. in water systems and water tanks that supply the toilet systems on trains, to assess the degree of contamination of such structures and to determine the effectiveness of decontamination.
\end{abstract}

Methods: A comparative pre-post ecological study was conducted from September 2006 to January 2011. A total of 1,245 water samples were collected from plumbing and toilet water tanks on passenger trains. The prevalence proportion of all positive samples was calculated. The unpaired t-test was performed to evaluate statistically significant differences between the mean load values before and after the decontamination procedures; statistical significance was set at $p \leq 0.05$.

Results: In the pre-decontamination period, $58 \%$ of the water samples were positive for Legionella. Only Legionella pneumophila was identified: $55.84 \%$ were serogroup 1, 19.03\% were serogroups $2-14$ and $25.13 \%$ contained both serogroups. The mean bacterial load value was $2.14 \times 10^{3} \mathrm{CFU} / \mathrm{L}$. During the post-decontamination period, $42.75 \%$ of water samples were positive for Legionella spp.; $98.76 \%$ were positive for Legionella pneumophila: $74.06 \%$ contained serogroup 1, 16.32\% contained serogroups $2-14$ and $9.62 \%$ contained both. The mean bacterial load in the post-decontamination period was $1.72 \times 10^{3} \mathrm{CFU} / \mathrm{L}$. According to the $t$-test, there was a statistically significant decrease in total bacterial load until approximately one and a half year after beginning the decontamination programme $(p=0.0097)$.

Conclusions: This study indicates that systematic environmental surveillance could be a useful approach for assessing the risk of exposure to Legionella bacteria, which still represents a public health threat. According to the study results, an environmental surveillance programme, followed by decontamination procedures where necessary, would decrease the total bacterial count, protecting the health of travellers and workers.

\footnotetext{
* Correspondence: sara.vincenti@rm.unicatt.it

${ }^{1}$ Institute of Hygiene, Università Cattolica del Sacro Cuore, L.go F. Vito 1,

00168 Rome, Italy

Full list of author information is available at the end of the article
}

\section{Biomed Central}

(c) 2012 Quaranta et al.; licensee BioMed Central Ltd. This is an Open Access article distributed under the terms of the Creative Commons Attribution License (http://creativecommons.org/licenses/by/2.0), which permits unrestricted use, distribution, and reproduction in any medium, provided the original work is properly cited. 


\section{Background}

Legionella pneumophila is increasingly recognized as a significant cause of sporadic and epidemic communityacquired and nosocomial pneumonia.

In recent years, our understanding of Legionnaires' Disease (LD) has improved substantially and new diagnostic and treatment strategies have been introduced [1].

To share knowledge and monitor trends of LD across Europe, the European Working Group for Legionella Infections (EWGLI) was established in 1986 to better protect the health of travellers by improving the detection and control of infection sources in European countries [2].

Members of EWGLI established a European surveillance scheme for travel-associated infections in 1987; this surveillance scheme, named EWGLINET in 2002, is the EU's surveillance network dedicated to collecting data on cases of LD in the EU, including travelassociated LD (TALD) [3,4].

Since April 2010, the programme has also been coordinated by European Centre for Disease Prevention and Control (ECDC), and the name of the scheme has changed to the European Legionnaires' Disease Surveillance Network (ELDSNet) [4].

In the beginning of July 2002, the European Guidelines for Control and Prevention of Travel Associated LD [5] were introduced in an attempt to standardise the investigation of clusters in EWGLINET countries and their Ministers of Health were asked to support the use of these guidelines.

In 2009, the EWGLINET surveillance scheme reported a total of 818 cases (794 confirmed and 24 presumptive) of travel-associated LD with onset of illness, which is a decrease of 52 cases compared with 2008 and is 129 fewer than in 2007. The countries that reported the most cases by country of residence were the UK $(n=173)$, Italy $(n=169)$ and the Netherlands $(n=109)$. These three countries have consistently reported the greatest number of cases to EWGLINET for several years [4].

The Italian National Surveillance System has reported that, in Italy, the incidence of Legionellosis has been increasing in the last ten years despite a slightly decreasing number of notified cases in the time periods from 20022004 and 2005-2006. In 2009, 1,200 cases of Legionellosis were diagnosed and reported (1,146 confirmed and 54 presumptive), with an incidence proportion of twenty cases per million (Figure 1) [6].

In Italy, in 2009, a total of 281 TALD cases, including both Italian and foreign tourists, were reported to the National Health Institute [6]. Among these, 178 cases of legionellosis concern to Italian Tourists. The $86 \%$ of them stayed at the hotels, the $5.6 \%$ stayed at camping and the $8,4 \%$ in other structures. The $10 \%$ of 178 cases have travelled in foreign locations.

Many studies describe the frequency and strength of Legionella spp. contamination in spa pools, natural pools, hotels and ships [7-17], but no study has been conducted that addresses the environmental monitoring of Legionella on board trains.

To protect the health of travellers and workers, the Health Service of Italian Railways and the Hygiene Institute of the Catholic University in Rome established for the first time an environmental surveillance programme to evaluate the degree of contamination on trains and the effectiveness and length of water tank decontamination.

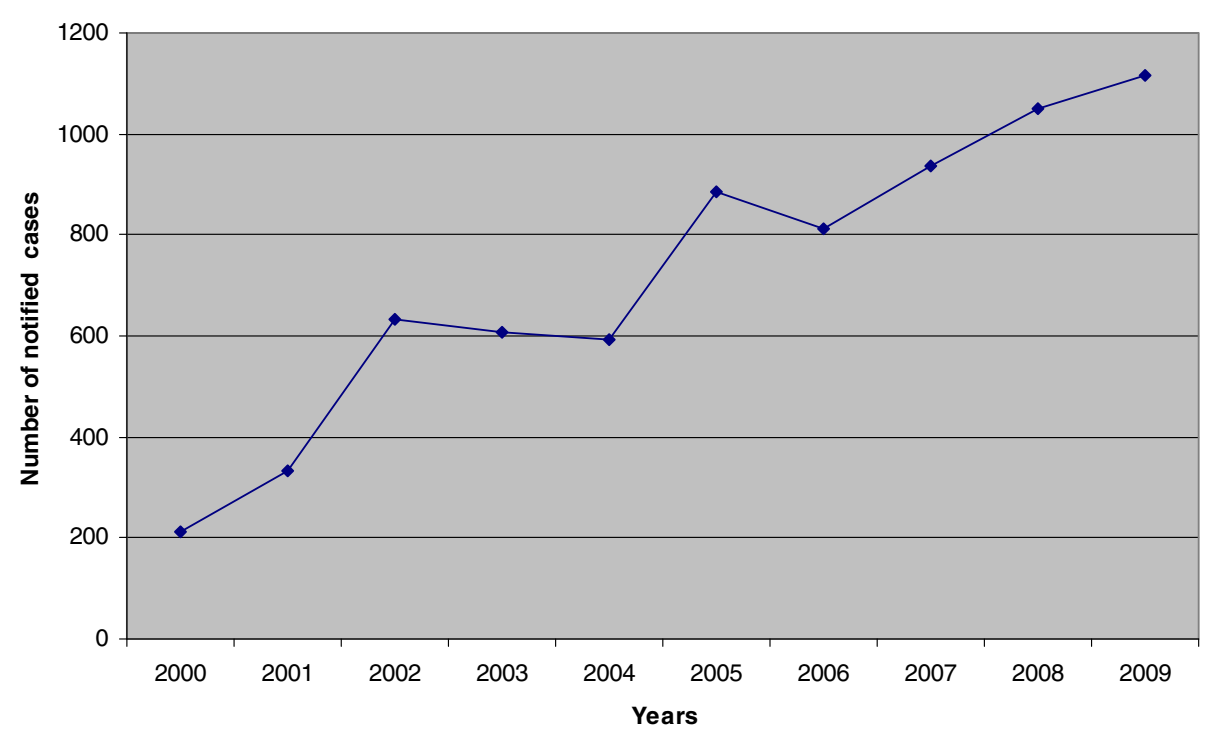

Figure 1 Cases of Legionellosis notified in Italy, 2000-2009 (Data source: Italian Ministry of Health). 
We have examined air conditioning plants and toilet water tanks, which are the primary sources of biological agents. The air conditioning plants on board Trenitalia trains are planned and built to avoid condensed water stagnation. Water is directly drained out of the trains by canalisations that prevent microorganism proliferation. Passenger trains contain water tanks made of steel or resin that supply hygienic services by falling water and they may have a varied capacity (from 200 to 1,800 litres) [18].

\section{Methods}

A comparative pre-post ecological study was conducted from September 2006 to January 2011.

\section{Water sampling and microbiological analysis}

Plumbing and toilet water tanks on passenger trains were examined.

Two samples were collected from every sampling site at a single time point: one sample was harvested immediately after the tap was switched on and without flaming for qualitative evaluation of the Legionella species and serogroup and the second sample was collected for quantitative determination (Legionella CFU/L of water) after the water ran for at least 5-10 minutes, which is more representative of the water flowing in the system. At least 6 to 12 water samples were collected weekly.

One litre of water was collected in sterile bottles with $0.01 \%$ sodium thiosulphate to neutralise any residual chlorine; water samples were transported in a suitable cool box, protected from direct light and processed within four hours after collection.

Microbiological detection of Legionella spp. was conducted following the methods described in the "Italian Guidelines for Legionellosis prevention and control" $[19,20]$.

Ten millilitres of the sample were first put into a sterile screw-capped Falcon tube, and then, a one-litre sample of water was concentrated by filtration on a $0.20 \mu \mathrm{m}$ pore-diameter cellulose membrane filter.

The membranes were aseptically removed and placed into the sterile screw-capped Falcon tube previously filled with $10 \mathrm{ml}$ of water sample collected; the material collected onto the membrane filter was vortex-mixed continuously for $2 \mathrm{~min}$.

Ten millilitres of the sample was divided into two aliquots of $5 \mathrm{ml}$ each; one aliquot was incubated at $50^{\circ} \mathrm{C}$ in a water bath for 30 minutes (treated sample) and the second aliquot remained at room temperature (nontreated sample).

Next, $0.1 \mathrm{ml}$ of the treated and non-treated samples was spread on a $90 \mathrm{~mm}$ Petri dish containing GVPCselective medium (glycine, polymyxin $\mathrm{B}$, vancomycin and cycloheximide). These plates were incubated at $37^{\circ} \mathrm{C}$ in a humidified atmosphere with $2.5 \% \mathrm{CO}_{2}$. Plates were evaluated for a maximum of 14 days before reporting them negative.

Suspected colonies that displayed a distinctive surface with an iridescent and faceted cut glass appearance were counted from each sampling. Gram staining was performed on the suspected colonies; weakly staining, gram-negative bacilli were observable. Suspicious colonies were sub-cultured both onto buffered charcoal yeast extract (BCYE) agar with cysteine and charcoal yeast extract agar (CYE Agar Base - Oxoid) for verification.

These plates were incubated at $37^{\circ} \mathrm{C}$ in a humidified atmosphere with $2.5 \% \mathrm{CO}_{2}$ for $\geq 2$ days.

The isolated colonies growing only on $\mathrm{BCYE}$, but that did not grow on CYE, were determined to be Legionella colonies. Subsequently, these colonies were serotyped by the agglutination Legionella Latex Test (Oxoid) that provides separate identification of $L$. pneumophila serogroup 1, L. pneumophila serogroups 2-14 and other species of Legionella spp. that have been implicated in human disease: L. longbeachae 1 and 2, L. bozemanii 1 and 2, L. dumoffii, L. gormanii, L. jordanis, L. micdadei and L. anisa.

According to the Italian Guidelines [19], quantitative evaluation (CFU/L) was performed considering the following items: the count of colonies growth in each plate, the concentration of the original sample and the dilutions successively made.

\section{Water supply on board trains and environmental decontamination procedures}

The water distributed in the toilets of passenger cars, both for the washbasin and for sanitary services, must have, at the time of supply, the characteristics required for human consumption. Because of the characteristics of hydraulic systems on board, these requirements cannot be fully insured, so water is labelled "no drinking".

Passenger railway cars are fitted with steel or resin tanks in which the total volume of water is variable depending on the type of car (ranging from 200 to 1,800 litres).

The water tanks are located under the car's roof and the water flows into the toilets by gravity.

Tanks are refilled at stations or through installation maintenance by jet spouts placed on side rails and discharge takes place through a special tap below the wagon.

When Legionella bacterial load was greater than $10^{3} \mathrm{CFU} / \mathrm{L}$, decontamination procedures were performed $[19,20]$. Decontamination was completed in September 2008 (pre-decontamination step = September 2006-September 2008), so October 2008 is considered the beginning of the post-decontamination period. 
The measures of supply reservoir and pipeline decontamination involve chemical de-scaling with $20 \%$ acetic acid and hyper-chlorination with $20 \mathrm{mg} / \mathrm{l}$ for 2 hours or $50 \mathrm{mg} / \mathrm{l}$ for 1 hour $[19,20]$, followed by washing to reach $0.2 \mathrm{mg} / \mathrm{l}$ of free residual chlorine concentration, or even replacement in limited cases of obvious damage.

\section{Statistical methods}

The prevalence proportion of all positive samples was calculated; the following bacterial load values were adopted to perform a statistical analysis: $<100 \mathrm{CFU} / \mathrm{L}$, 100-999 CFU/L, 1,000-9,999 CFU/L, >10,000 CFU/L.

The unpaired $t$-test was performed to evaluate statistically significant differences between the mean load values before and after the decontamination procedures; statistical significance was set at $p \leq 0.05$.

\section{Results}

The overall number of water samples collected from different trains and analysed from September 2006 to January 2011 was 1,245 (Table 1). Of those, 679 were collected during the pre-decontamination period.

In the pre-decontamination period, $58 \%$ of water samples were positive for Legionella and only L. pneumophila was identified; $55.84 \%$ contained serogroup 1, $19.03 \%$ contained serogroups $2-14$ and $25.13 \%$ contained both serogroups.

The mean bacterial load value was $2.14 \times 10^{3} \mathrm{CFU} / \mathrm{L}$; $17.51 \%$ of positive samples had a load value $<100$, $39.34 \%$ ranged from 100 to $999,35.03 \%$ ranged from 1,000 to 9,999 and $8.12 \%$ were $>10,000 \mathrm{CFU} / \mathrm{L}$.

During the post-decontamination period, 566 water samples were collected and analysed: $42.75 \%$ were positive for Legionella and Legionella pneumophila was identified in $98.76 \%$ of the positive samples; $74.06 \%$ contained serogroup 1, 16.32\% contained serogroups 214 and $9.62 \%$ contained both serogroups.

The mean bacterial load of positive samples in the post-decontamination period was $1.72 \times 10^{3} \mathrm{CFU} / \mathrm{L}$ :
$5.79 \%$ had a load value $<100,50 \%$ were between 100 and 999, 35.12\% were between 1,000, and 9,999 and 9.09\% were $>10,000 \mathrm{CFU} / \mathrm{L}$.

The unpaired $t$-test was performed to compare postdecontamination results to pre-decontamination levels; there was a statistically significant decrease in total bacterial load after January 2009: $p=0.0309$ (Table 2). The statistically significant decrease in total bacterial load continued until March 2010 ( $p=0.0097$ ), confirming the intervention's effectiveness until approximately one and a half years after beginning the decontamination period.

\section{Discussion}

Several studies describe the frequency of Legionella spp. contamination in spa pools, natural pools and hotels [79]. Cases of LD are also well documented among cruise ship passengers [9-17]. To date, this is the first study concerning the environmental monitoring of Legionella on board trains.

This study demonstrates the necessity for periodic evaluation on trains to assess the potential contamination of $L e$ gionella spp., with the aim to drive decontamination efforts in the absence of specific guidelines. We hypothesized that an environmental surveillance programme, followed by decontamination procedures when necessary, would decrease the total bacterial load, thereby protecting the health of travellers and workers.

This study demonstrated a statistically significant decrease in total bacterial load after decontamination procedures. The $t$-test indicated a decrease in bacterial load since October 2008, with statistical significance from January 2009 to March 2010, suggesting that a disinfection treatment performed every one and a half years could reduce environmental contamination.

Moreover, this study demonstrated a decrease in Legionella-positive samples after decontamination procedures: $58 \%$ in the pre-decontamination period and $42.75 \%$ in post one were positive for Legionella. Although there was

\section{Table 1 Results of the microbiological analysis performed on the water samples collected}

\begin{tabular}{|c|c|c|c|}
\hline & Pre-decontamination period & Post-decontamination period & Total \\
\hline Number of water samples analysed & 679 (54.538\% of total samples analyzed) & 566 (45.462\% of total samples analyzed) & 1245 \\
\hline Number of samples positive for Legionella spp. & $394(58.027 \%)$ & $242(42.756 \%)$ & 636 \\
\hline Number of samples positive for L. pneumophila 1 & $220(55.838 \%)$ & $177(73.140 \%)$ & 397 \\
\hline Number of samples positive for L. pneumophila 2 -14 & $75(19.036 \%)$ & $39(16.116 \%)$ & 114 \\
\hline Number of samples positive for L. pneumophila 1 and $2-14$ & $99(25.127 \%)$ & $23(9.504 \%)$ & 122 \\
\hline Number of samples positive for Legionella other species & $0(0.000 \%)$ & $3(1.240 \%)$ & 3 \\
\hline Number of samples with load values < 100 CFU/L & $69(17.513 \%)$ & $14(5.785 \%)$ & 83 \\
\hline Number of samples with load values 100-999 CFU/L & $155(39.340 \%)$ & $121(50.000 \%)$ & 276 \\
\hline Number of samples with load values 1,000-9,999 CFU/L & $138(35.025 \%)$ & $85(35.124 \%)$ & 223 \\
\hline Number of samples with load values $\geq 10,000$ CFU/L & $32(8.122 \%)$ & $22(9.091 \%)$ & 54 \\
\hline
\end{tabular}


Table 2 Effectiveness of decontamination on Legionella bacterial loading

\begin{tabular}{|c|c|c|c|c|}
\hline Month & $\begin{array}{l}\text { Mean of load value (CFU/I) } \\
\text { (post-decontamination period) }\end{array}$ & $\begin{array}{l}\text { Mean of bacterial load in } \\
\text { natural logarithmic numbers }\end{array}$ & $\mathbf{t}$ & $p$ \\
\hline October 2008 & 992.2414 & 6.9000 & 0.6591 & 0.2550 \\
\hline November 2008 & 583.8235 & 6.3696 & 1.1843 & 0.1183 \\
\hline December 2008 & 397.0000 & 5.9839 & 1.6083 & 0.0541 \\
\hline January 2009 & 320.1613 & 5.7688 & 1.8698 & 0.0309 \\
\hline February 2009 & 295.1282 & 5.6874 & 2.1259 & 0.0169 \\
\hline March 2009 & 306.3265 & 5.7247 & 2.3673 & 0.0091 \\
\hline April 2009 & 315.3801 & 5.7538 & 2.5402 & 0.0056 \\
\hline May 2009 & 295.0256 & 5.6871 & 2.7428 & 0.0031 \\
\hline June 2009 & 417.9909 & 6.0355 & 2.7060 & 0.0035 \\
\hline July 2009 & 498.4615 & 6.2115 & 2.6624 & 0.0039 \\
\hline August 2009 & 554.6850 & 6.3184 & 2.6735 & 0.0038 \\
\hline September 2009 & 592.1561 & 6.3838 & 2.6817 & 0.0037 \\
\hline October 2009 & 753.6237 & 6.6249 & 2.4677 & 0.0069 \\
\hline November 2009 & 752.5163 & 6.6234 & 2.5500 & 0.0055 \\
\hline December 2009 & 748.6751 & 6.6183 & 2.6023 & 0.0047 \\
\hline January 2010 & 726.0479 & 6.5876 & 2.7144 & 0.0034 \\
\hline February 2010 & 934.4538 & 6.8400 & 2.3195 & 0.0103 \\
\hline March 2010 & 962.5000 & 6.8695 & 2.3432 & 0.0097 \\
\hline April 2010 & 1369.3270 & 7.2221 & 1.3341 & 0.0912 \\
\hline May 2010 & 1314.9530 & 7.1816 & 1.4680 & 0.0712 \\
\hline June 2010 & 1521.4860 & 7.3274 & 1.0917 & 0.1376 \\
\hline July 2010 & 1482.9550 & 7.3018 & 1.1885 & 0.1174 \\
\hline August 2010 & 1707.7110 & 7.4429 & 0.7837 & 0.2167 \\
\hline September 2010 & 1697.6230 & 7.4370 & 0.8044 & 0.2107 \\
\hline October 2010 & 1684.2690 & 7.4291 & 0.8432 & 0.1996 \\
\hline November 2010 & 1635.7890 & 7.3999 & 0.9556 & 0.1697 \\
\hline December 2010 & 1719.8530 & 7.4500 & 0.8037 & 0.2109 \\
\hline January 2011 & 1721.6250 & 7.4510 & 0.8141 & 0.2079 \\
\hline
\end{tabular}

[In Table 2 are reported the results of the unpaired t-tests performed to compare the mean value of the bacterial load in the pre-decontamination period (grand mean: $2142.7840 \mathrm{CFU} / \mathrm{L}-7.6698$ in logarithmic value) with the ones of the post-decontamination period].

a decrease in the total Legionella-positive samples, we observed an increase of Legionella serogroup 1 (55.84\% pre- vs. $74.06 \%$ post-decontamination), which is responsible for approximately $70 \%$ of Legionella infections in Europe [21]. This increase could have been due to the development of a protective biofilm, especially when load values were high. As demonstrated in this study, the disinfection treatments were more effective when the bacterial load was lower $(17.51 \%$ of positive samples with a load value $<100 \mathrm{CFU} / \mathrm{L}$ in pre- vs. $5.79 \%$ in post-decontamination).

Even if hyper-chlorination of the water is consistently performed, this approach is particularly appropriate for the treatment and removal of planktonic cultures of $L$. pneumophila, but remains ineffective against sessile communities of the bacterium [22].
This study suggests that the resistance to chlorination of L. pneumophila serogroup 1 could be due to the biofilm that facilitates a higher tolerance to the disinfectant. In fact, we observed limestone deposits in different water tanks in which the biofilm could have been developed. Environmental strains could develop a resistance mechanism to chlorine-based disinfection treatments, so these decontamination procedures are not completely appropriate for removing the bacterium from plumbing and tanks. As these procedures do not lead to a definitive solution to the problem, we suggest that mechanical cleaning could increase the effectiveness and length of chemical decontamination procedures, thereby reducing bacterial load values and increasing the amount of time that the water can be considered safe. 
We aimed to highlight that environmental surveillance represents an evidence-based approach for evaluating the contamination of the water supply on board trains. This work stresses the effectiveness of decontamination and, above all, provides information about the required frequency of disinfection procedures to achieve a statistically significant decrease in total bacterial load.

Periodic environmental surveillance could be a useful approach for assessing the risk of exposure to Legionella bacteria, which still poses a threat to public health. Legionella spp. are opportunists par excellence and are therefore especially dangerous for vulnerable individuals (e.g., older people, current tobacco smokers, immunecompromised or immune-suppressed persons, patients with chronic degenerative diseases and transplanted people).

Our purpose is to ensure the safety of the passengers and the workers on board trains by defining proper preventive measures to be implemented with an established frequency.

The primary limitation of this study concerns the use of the $t$-test; a paired $t$-test was not performed because this study focused on the general trend of contamination/decontamination on board trains as opposed to a specific sampling site.

Moreover in this study we analyzed only environmental data because we were given the responsibility of doing only the environmental surveillance; in fact, clinical surveillance was carried out by other institutions and, up to date, we have no information about cases of Legionellosis linked to our environmental data.

The lengthy time period of the environmental surveillance and the large number of water samples collected and analysed represent a point of strength in this study.

\section{Conclusions}

Public health programmes should focus on reducing the risk for LD among travellers.

In addition to cruise ships and ferries [16], the routine monitoring of water on board trains must be considered an essential measure of primary prevention for guaranteeing water safety and, consequently, to avoid cases of LD. For these reasons, the drafting of guidelines for LD prevention on public transportation may be necessary to protect the health of travellers and workers. According to our experience, it is necessary to pay close attention to water quality on board trains, especially after decontamination procedures to prevent bacterial colonization.

Although the eradication of Legionella spp. in plumbing and water tanks is difficult to achieve, our approach can be considered an evidence-based method for assessing and managing Legionella infection risk on trains.

The air conditioning plants on board Trenitalia trains are designed to avoid air conditioner condensation drip.
The particular characteristics of water supply facilities on trains, which work by gravity at a low pressure, and the lack of showers reduce the possibility of the formation of aerosol, which is potentially dangerous for Legionellosis. Nevertheless, Italian Railways have carried out the present study in collaboration with Catholic University in Rome and the positive results may improve future train sanitation following the practical measures described in detail in this article.

\section{Abbreviations}

CFU: Colony forming unit; CFU/L: Colony forming unit/litre.

\section{Competing interests}

The authors declare that they have no competing interests.

\section{Authors' contributions}

GQ participated in the design of the study, contributed to draft the manuscript and performed the statistical analysis. SV performed the microbiological analysis, conceived of the study and helped to draft the manuscript. AMF conceived of the study and helped to manage the database and to draft the manuscript. FB performed the microbiological analysis. RS performed the microbiological analysis. $\mathrm{CT}$ performed the microbiological analysis. MDG helped to manage the database and draft the manuscript. GC,CC, MA and PDN conceived of the study and participated in its design and coordination. EM conceived of the study and participated in its design and coordination, allowing the surveillance on board train. WR conceived of the study and participated in its design and coordination. PL conceived of the study, participated in its design and coordination, carried out the surveillance and helped to draft the manuscript. All authors read and approved the final manuscript.

\section{Author details}

${ }^{1}$ Institute of Hygiene, Università Cattolica del Sacro Cuore, L.go F. Vito 1, 00168 Rome, Italy. ${ }^{2}$ RFI (Italian Railway) Health Service, Via F. A. Pigafetta 3, 00154 Rome, Italy. ${ }^{3}$ Trenitalia Environmental Work Quality and Safety, Via F. A. Pigafetta 3, 00154 Rome, Italy.

Received: 20 January 2012 Accepted: 30 July 2012

Published: 7 August 2012

\section{References}

1. Carratalà J, Garcia-Vidal C: An update on Legionella. Curr Opin Infect Dis 2010, 23:152-157.

2. Ricketts K, Joseph CA, Yadav R: Travel-associated Legionnaires' Disease in Europe in 2008. On behalf of the European Working Group for Legionella Infections. Euro Surveill 2010, 15(21):19578. http//www. eurosurveillance.org/NiewArticle.aspx?Articled $=19578$.

3. Ricketts KD, Joseph CA: The impact of new guidelines in Europe for the control and prevention of travel-associated Legionnaires' Disease. On behalf of the European Working Group for Legionella Infections. Int J Hyg Environ Health 2006, 209:547-552.

4. Joseph CA, Ricketts KD, Yadav R, Patel S, on behalf of the European Working Group for Legionella Infections: Travel-associated Legionnaires' Disease in Europe in 2009. Euro Surveill 2010, 15(41):19683. http://www. eurosurveillance.org/ViewArticle.aspx?Articled=19683.

5. European Working Group of Legionella Infections: European Guidelines for control and prevention of travel associated Legionnaires' Disease. 2002. http:// www.hpa.org.uk/Topics/InfectiousDisease/InfectionsAZ/LegionnairesDisease/ Guidelines/legiEuropeanAdviceandGuidance.

6. Rota MC, Caporali MG, Giannitelli S, Mandarino G, Scaturro M, Ricci ML: Rapporto annuale sulla Legionellosi in Italia nel 2009. Not Ist Super Sanità 2010, 239:3-9.

7. Huhn GD, Adam B, Ruden R, Hilliard L, Kirkpatrick P, Todd J, Crafts W, Passaro D, Dworkin MS: Outbreak of travel-related pontiac fever among hotel guests illustrating the need for better diagnostic tests. J Travel Med 2005, 12(4):173-179.

8. Modi A, Gardner J, Lighton L, Coetzee N: Pontiac fever outbreak associated with a spa-pool. United Kingdom Euro Surveill 2008, 24(30):13. 
9. Guyard C, Low DE: Legionella infections and travel associated legionellosis. Travel Med Infect Dis 2011, 9(4):176-186.

10. Jernigan DB, Hofmann J, Cetron MS, Genese CA, Nuorti JP, Fields BS, Benson RF, Carter RJ, Edelstein PH, Guerrero IC, Paul SM, Lipman HB, Breiman R: Outbreak of Legionnaires' Disease among cruise ship passengers exposed to a contaminated whirlpool spa. Lancet 1996, 24(3479000):494-499.

11. Rowbotham TJ: Legionellosis associated with ships: 1977 to 1997. Commun Dis Public Health 1998, 13:146-151.

12. Minooee A, Rickman LS: Infectious diseases on cruise ships. Clin Infect Dis 1999, 29(4):737-743.

13. Cayla JA, Maldonado R, Gonzales J, Pellicer T, Ferrer D, Pelaz C, Gracia J, Baladron B, Plasencia A: Legionellosis study group: a small outbreak of Legionnaires's Disease in a cargo ship under repair. Eur Resp 2001, 176:1322-1327.

14. Regan CM, McCann B, Syed Q, Christie P, Joseph C, Colligan J, McGaffin A: Outbreak of Legionnaires' Disease on a cruise ship: lessons for International surveillance and control. Commun Dis Public Health 2003, 62:152-156.

15. MMWR Morb Mortal Wkly Rep: Cruise-ship-associated Legionnaires disease. Centers Dis Control Prev (CDC) 2005, 54(45):1153-1155.

16. Azara A, Piana A, Sotgiu G, Dettori M, Deriu MG, Masia MD, Are BM, Maresu E: Prevalence study of Legionella spp. contamination in ferries and cruise ships. BMC Public Health 2006, 18(6):100.

17. Goutziana G, Mouchtouri VA, Karanika M, Kavagias A, Stathakis NE, Gorgoulianis K, Kremastinou J, Hadjichristodoulou C: Legionella species colonization of water distribution systems, pools and air conditioning systems in cruise ships and ferries. BMC Public Health 2008, 24(8):390.

18. Munafò E, Accorsi M, Del Nord P, Mansi A, Laurenti P: Guidelines for the prevention and control of the Legionella spp contamination in the water tanks of railways cars. In Proceedings of the Union International des Services Medicaux des Chemins de Fer (UIMC) Congress. Brussels, 2007.

19. Gazzetta Ufficiale n.103 del 5 maggio: Linee guida per la prevenzione e il controllo della Legionellosi. 2000. http://www.guritel.it/free-sum/ARTI/2000/ 05/05/sommario.html.

20. Gazzetta Ufficiale n.29 del 5 febbraio: Linee guida recanti indicazioni ai laboratori con attività di diagnosi microbiologica e controllo ambientale della Legionellosi. 2005. http://www.guritel.it/free-sum/ARTI/2005/02/05/sommario. html.

21. World Health Organization: Legionella and the prevention of legionellosis. 2007. http://www.who.int/water_sanitation_health/emerging/legionella.pdf.

22. Cooper IR, Hanlon GW: Resistance of Legionella pneumophila serotype 1 biofilms to chlorine-based disinfection. J Hosp Infect 2010, 74:152-159.

doi:10.1186/1471-2458-12-618

Cite this article as: Quaranta et al:: Legionella on board trains:

effectiveness of environmental surveillance and decontamination. $B M C$

Public Health 2012 12:618.

\section{Submit your next manuscript to BioMed Central and take full advantage of:}

- Convenient online submission

- Thorough peer review

- No space constraints or color figure charges

- Immediate publication on acceptance

- Inclusion in PubMed, CAS, Scopus and Google Scholar

- Research which is freely available for redistribution 